\title{
Neonatal bone marrow transplantation for severe combined immunodeficiency
}

\author{
L Kane, A R Gennery, B N A Crooks, T J Flood, M Abinun, A J Cant
}

\begin{abstract}
Aims-To evaluate outcome following neonatal bone marrow transplantation (BMT) for severe combined immunodeficiency (SCID) when there is a family history of a previously affected sibling, and to compare results with those published for in utero BMT.

Methods-A retrospective review of cases referred and transplanted between 1987 and 1999, focusing on infectious and graft versus host disease (GvHD) complications after BMT, and T and B lymphocyte function. Thirteen patients received 18 stem cell transplants: four whole marrow, one cord blood, 10 parental $T$ cell depleted (TCD) haplo-identical, and three TCD unrelated donor BMT. Nine were conditioned with busulphan and cyclophosphamide.
\end{abstract}

Results-All are alive and well (six months to 11.5 years after BMT). Six had grade I-II acute GvHD and two chronic GvHD (now resolved). Three had a top up BMT for poor $T$ cell function, one had a third BMT for graft failure and chronic GvHD, and one had a third BMT for graft failure. Twelve have good in vitro proliferation to $T$ cell mitogens, and all have normal serum IgA levels. Three receive intravenous immunoglobulin; for one of these, it is less than one year since BMT. Nine are above the 2 nd centile, and 10 of 12 old enough to be assessed have normal neurodevelopment.

Conclusion-These results are better than those published for in utero BMT for SCID. Early postnatal BMT should be the preferred option in neonatal SCID.

(Arch Dis Child Fetal Neonatal Ed 2001;85:F110-F113)

Keywords: severe combined immunodeficiency; bone marrow transplantation; in utero transplantation

Department of Paediatric Immunology, Newcastle General Hospital, Newcastle upon Tyne, UK

L Kane

A R Gennery

B N A Crooks

T J Flood

M Abinun

A J Cant

Correspondence to:

Dr Gennery, Department of

Paediatric Immunology,

Newcastle General Hospital,

Westgate Road, Newcastle

upon Tyne NE4 6BE, UK

ARGennery@aol.com

Accepted 8 March 2001 common gamma chain $(\gamma),{ }^{4}$ Janus associated kinase 3 (JAK3), ${ }^{5}$ recombination activation gene (RAG), ${ }^{6}$ interleukin 7 receptor alpha (IL7R $\alpha),{ }^{7}$ and adenosine deaminase (ADA). ${ }^{8}$ This allows first trimester antenatal diagnosis when a positive family history of SCID alerts to this possible diagnosis. In utero BMT has been proposed as the best treatment for such patients. Suggested advantages of in utero BMT include the physiologically sterile uterine environment and immaturity of the fetal immune system enabling engraftment without the use of cytotoxic conditioning regimens. ${ }^{9}$ Two series of six and four patients ${ }^{10-12}$ (F Porta, personal communication) and one case report ${ }^{13}$ of in utero transplants have been published. These contain little information on long term immune function, particularly B cell function, yet failure of B cell engraftment and function usually results in long term dependence on replacement intravenous immunoglobulin (IVIG). Furthermore, the results of in utero BMT have been compared with the results of transplanting all infants with SCID including those diagnosed after the neonatal period when they are seriously ill with infection. It is more appropriate to compare the results of in utero BMT with those in children diagnosed at birth because of a positive family history and treated with BMT in the neonatal period. Previous studies have shown excellent results for BMT for neonatal SCID as a subgroup of the overall series reported. ${ }^{14}$ Results of BMT performed in the newborn have not been published separately before, however, and therefore the appropriate comparison has been difficult. This study looks at the results of transplanting infants in the postnatal period after early diagnosis because of a family history of SCID.

\section{Methods}

Case notes were retrospectively reviewed to identify patients treated for SCID. Diagnosis and time to admission were noted. Type of donor, marrow manipulation, and cytoreductive chemotherapy were recorded. Time to engraftment, complications after BMT, and molecular engraftment studies were compared. Immune function was assessed after BMT by monitoring immunoglobulin levels and $\mathrm{T}$ cell function. $\mathrm{T}$ and $\mathrm{B}$ lymphocyte numbers were quantified by flow cytometry (FACScan, Becton Dickinson, Oxford, UK). T cell function was determined using standard in vitro proliferations against the mitogen phytohaemagglutinin. Serum $\operatorname{IgG}, \operatorname{IgA}$, and $\operatorname{IgM}$ were measured by rate nephelometry. Cellular molecular genetic analysis was performed on cells separated by flow cytometry. DNA was extracted by 
salting out followed by gel electrophoresis and automated fluorescence analysis. Finally, long term graft function, growth, and neurodevelopment were recorded. At each visit, a full blood count, determination of urea and electrolytes, liver function tests, determination of lymphocyte surface markers and immunoglobulin levels, direct Coombs test, and determination of isohaemagglutinins were performed. $\mathrm{T}$ cell proliferation assays were performed yearly. Reviews and investigations were more frequent if clinically indicated.

PATIENTS

Between April 1987 and September 1999, 40 patients were referred with SCID $\left(\mathrm{T}^{-} \mathrm{B}^{+}, \mathrm{T}^{-} \mathrm{B}^{-}\right.$ or ADA deficiency). Thirteen (32\%) were diagnosed in the neonatal period because of a family history of a previously affected infant. Twelve of these families had had previous contact with the unit. Seven infants had $\mathrm{T}^{-} \mathrm{B}^{+}$ SCID, three had $\mathrm{T}^{-} \mathrm{B}^{-}$SCID, and three had ADA deficiency (table 1). All were admitted at between 0 and 30 days of age (median 3 days) and nursed under laminar flow. None had evidence of pre-existing infection.

The 13 infants received a total of 18 BMTs. Initial BMT was performed at between 7 and 68 days, except for one infant with ADA deficiency, who was treated with poly (ethylene glycol) ADA initially before BMT at 93 days. Three patients with $\mathrm{T}^{-} \mathrm{B}^{-}$SCID received top up BMTs for poor $T$ cell function; one (patient 7 ) was given a third BMT for graft failure and severe chronic graft versus host disease (GvHD), and one (patient 9) received a third BMT for graft failure. The 13 initial allogeneic stem cell transplantations consisted of two with HLA-identical sibling whole marrow, one with an HLA-identical sibling cord blood (stored after the birth of an unaffected child), one with phenotypically matched paternal whole marrow, two with unrelated donor $\mathrm{T}$ cell depleted (TCD) marrow, and seven with haplo-identical paternal TCD marrow (table 1). The three "top up" BMTs (patients 4, 7, and 9) used the same donors as in the initial transplants. Haplo-identical paternal TCD marrow was used for the third BMT of patient 7; haploidentical maternal TCD marrow was used for the third BMT of patient 9. T cell depletion was performed in vitro using Campath $1 \mathrm{M}$ for patients 1-12. Positive CD $34^{+}$cell selection using the CliniMACS device (Miltenyi BioTec) was used for patient 13, the top up BMT of patient 9 , and the third BMT of patients 7 and 9.

Four patients received no cytoreductive conditioning before BMT. Nine underwent conditioning according to consensus European protocols. Seven of these received busulphan 8 $\mathrm{mg} / \mathrm{kg}$, and the two receiving unrelated donor marrow received busulphan $16 \mathrm{mg} / \mathrm{kg}$. All nine were given cyclophosphamide $200 \mathrm{mg} / \mathrm{kg}$. One patient (5) also received rabbit anti-thymocyte globulin (ATG) $6 \mathrm{mg} / \mathrm{kg}$, as maternofetal engraftment was suspected. No conditioning was used in the three top up BMTs, but patient 7 received busulphan $16 \mathrm{mg} / \mathrm{kg}$, cyclophosphamide $200 \mathrm{mg} / \mathrm{kg}$, and rabbit ATG $6 \mathrm{mg} / \mathrm{kg}$, and patient 9 received busulphan $16 \mathrm{mg} / \mathrm{kg}$ and cyclophosphamide $200 \mathrm{mg} / \mathrm{kg}$ before the third BMT (table 1).

Length of admission for those receiving whole marrow ranged from 16 to 192 days (median 58 days), and those who received TCD marrow stayed 1-301 days (median 168 days). The two shortest admissions of one and 16 days were for two of the top up BMTs. Clinical review after discharge occurred every six weeks until one year after BMT, every three months until two years after BMT, and annually thereafter.

\section{Results}

All patients are alive and well with follow up of six months to 11.5 years (median three years). After BMT, five patients had grade II acute GvHD, and one had grade I acute GvHD. Two patients with grade II acute GvHD developed chronic GvHD. Patient 6 had limited skin GvHD and patient 7 had extensive skin and gut GvHD. All GvHD has now resolved. Other complications in the period after BMT included a paradoxical septic embolus, resulting in left renal infarction and a left sided stroke (patient 4), rotavirus enteritis (patient 7 second BMT), and Escherichia coli sepsis (patient 13). Viral infection after BMT occurred with rotavirus (patients 1 and 7 ), adenovirus

Table 1 Patient diagnoses and bone marrow transplant details

\begin{tabular}{|c|c|c|c|c|c|c|c|c|}
\hline Patient & Phenotype & $\begin{array}{l}\text { Molecular } \\
\text { diagnosis }\end{array}$ & Age at BMT & Type of BMT & Conditioning regimen & $\begin{array}{l}\text { Admission } \\
\text { length (days) }\end{array}$ & $\begin{array}{l}\text { Time after last } \\
\text { BMT (years) }\end{array}$ & $\begin{array}{l}\text { Chimerism } \\
(T / B)\end{array}$ \\
\hline 1 & $\mathrm{~T}^{-} \mathrm{B}^{+}$ & $\operatorname{cgc}$ & 68 days & Haplo TCD & Bu8;Cy200 & 226 & 11.5 & $\mathrm{D} /$ mixed \\
\hline 2 & $\mathrm{~T}^{-} \mathrm{B}^{+} \mathrm{NK}^{+}$ & Unknown & 38 days & Haplo TCD & Bu8;Cy200 & 206 & 7.3 & $\mathrm{D} / \mathrm{D}$ \\
\hline 3 & $\mathrm{~T}^{-} \mathrm{B}^{+} \mathrm{NK}^{+}$ & Unknown & 35 days & Haplo TCD & Bu8;Cy200 & 210 & 6.7 & $\mathrm{D} / \mathrm{R}$ \\
\hline \multirow[t]{2}{*}{4} & $\mathrm{~T}^{-} \mathrm{B}-\mathrm{NK}^{+}$ & Unknown & 48 days & Pheno Whole & Nil & 192 & & \\
\hline & & & 2 years 5 months & Pheno Whole & Nil & 16 & 3 & $\mathrm{D} /$ mixed \\
\hline 5 & $\mathrm{~T}^{-} \mathrm{B}^{+} \mathrm{NK}^{+}$ & Unknown & 58 days & Haplo TCD & Bu8;Cy200;ATG6 & 171 & 4.8 & $\mathrm{D} /$ mixed \\
\hline 6 & $\mathrm{~T}^{-} \mathrm{B}^{-} \mathrm{NK}^{-}$ & $\mathrm{ADA}$ & 93 days & URD TCD & Bu16;Cy200 & 230 & 4.3 & $\mathrm{D} /$ mixed \\
\hline \multirow[t]{3}{*}{7} & $\mathrm{~T}^{-} \mathrm{B}^{-} \mathrm{NK}^{-}$ & Unknown & 66 days & URD TCD & Bu8;Cy200 & 201 & & \\
\hline & Radiosensitive & & 302 days & URD TCD & Nil & 214 & & \\
\hline & & & 2.5 years & Haplo TCD & Bu16;Cy200;ATG6 & 157 & 1.5 & D/Unknown \\
\hline 8 & $\mathrm{~T}^{-} \mathrm{B}^{+} \mathrm{NK}^{+}$ & Unknown & 45 days & Haplo TCD & Bu8;Cy200 & 172 & 3.2 & $\mathrm{D} / \mathrm{R}$ \\
\hline \multirow[t]{3}{*}{9} & $\mathrm{~T}^{-} \mathrm{B}^{-} \mathrm{NK}^{+}$ & RAG2 & 41 days & Haplo TCD & Bu8;Cy200 & 144 & & \\
\hline & & & 1 year 5 months & Haplo TCD & Nil & 1 & & \\
\hline & & & 2 years 1 month & Haplo TCD & Bu16;Cy200 & 64 & 0.5 & D/Unknown \\
\hline 10 & $\mathrm{~T}^{-} \mathrm{B}^{-} \mathrm{NK}^{-}$ & $\mathrm{ADA}$ & 39 days & Sib Whole & Nil & 58 & 2.3 & $\mathrm{D} /$ mixed \\
\hline 11 & $\mathrm{~T}^{-} \mathrm{B}^{-} \mathrm{NK}^{-}$ & ADA & 33 days & Sib Whole & Nil & 83 & 2 & $\mathrm{D} /$ mixed \\
\hline 12 & $\mathrm{~T}^{-} \mathrm{B}^{-} \mathrm{NK}^{+}$ & Unknown & 7 days & Sib Cord Blood & Nil & 56 & 1.6 & $\mathrm{D} /$ mixed \\
\hline 13 & $\mathrm{~T}^{-} \mathrm{B}^{+}$ & $\mathrm{cgc}$ & 45 days & Haplo TCD & Bu8;Cy200 & 168 & 1.3 & $\mathrm{D} / \mathrm{R}$ \\
\hline
\end{tabular}

cgc, Common interleukin gamma chain deficiency; ADA, adenosine deaminase deficiency; RAG2, recombination activation gene 2 deficiency; Haplo, haplo-identical; TCD, T cell depleted; Pheno, phenotypic; URD, unrelated donor; Sib, sibling; Bu, busulfan; Cy, cyclophosphamide; ATG, anti-thymocyte globulin; BMT, bone marrow transplant; T/B, T lymphocytes/B lymphocytes; D, donor; R, recipient. 
(untyped in patient 2, type 2 in patient 11), echovirus 25 (patient 1), parainfluenza 3 (patient 3), cytomegalovirus (patient 3), and influenza type A (patient 13). Patient 7 developed autoimmune thrombocytopenia and anaemia, which resolved and improved respectively with high dose IVIG treatment.

Those who were conditioned had neutrophil engraftment (count $>0.5 \times 10^{9} / 1$ for three consecutive days) by 21-39 days (median 32 days) and platelet engraftment (unsupported count $>50 \times 10^{9} / 1$ for three consecutive days) by 11-106 days (median 21 days). T lymphocyte counts $>200 / \mathrm{ml}$ were achieved by whole marrow recipients by $12-32$ days after BMT (median 18 days), and TCD marrow recipients attained this level by 61-153 days (median 117 days). All patients show a gain of donor allelles for $\mathrm{T}$ cells on split cell molecular genetic analysis. In vitro $\mathrm{T}$ cell proliferation to phytohaemagglutinin is normal in 12 patients, and normalising in the other (patient 9). B lymphocyte chimerism has been assessed in 11 patients, eight of whom have full or partial gain of donor allelles. One patient has full donor chimerism in all cell lines.

All patients produce normal levels of IgA, and all except patient 4 have normal IgM levels. Seven have normal specific IgG antibody responses to tetanus and $\mathrm{Hib}$ after immunisation, three further patients $(10,12$, and 13) have ceased IVIG treatment, and IgG responses after vaccination are currently being evaluated. None have normal pneumococcal IgG antibody levels. Seven have normal isohaemagglutinin titres. Only three patients remain on IVIG. One (patient 4) who was not conditioned receives long term IVIG (more than one year after BMT). She has low B cell numbers and low IgM but normal IgA levels with low isohaemagglutinin titres. One patient (9) who had a third BMT less than one year ago remains on IVIG, with low isohaemagglutinin titres but has normal IgM and IgA levels. The third (patient 7 ) remains on high dose IVIG for thrombocytopenia and autoimmune haemolytic anaemia. He has low isohaemagglutinin titres but has normal IgM and IgA levels. For seven of eight patients who received haploidentical parental TCD marrow, it is more than one year since the BMT, and six have normal $\mathrm{B}$ and $\mathrm{T}$ lymphocyte function (table 1).

The height of six patients is on the 50th centile, that of five is between the $2 \mathrm{nd}$ and 50th centiles, and that of two is below the 2 nd centile. One patient ( 7 ) is below the 0.4 th centile for height and weight secondary to previous gastrointestinal chronic GvHD. Twelve children are old enough to undergo developmental assessment; 10 are normal, with those who are old enough are attending mainstream school. Patient 4 had poor communication and interactive skills and inattention, which have improved with input from portage workers and occupational therapists, so she attends mainstream school. Patient 10 had motor milestone delay, also noted in his otherwise normal sibling.

\section{Discussion}

Compared with the results of transplanting neonates before acquisition of infective organisms, the results of in utero transplantation have not lived up to expectations. Touraine et $a l^{10}$ reported on six in utero transplants using fetal liver and thymic epithelial cells; four survived to birth. Two died after transplant infusion, which resulted in abortion, and the two treated for thalassaemia and Niemann-Pick type A disease were not cured. Of the two treated for primary immunodeficiency, one has sclerosing cholangitis, and the other required seven postnatal top up transplants during a 16 month isolation. Long term immune function, growth, and development details are not available. Porta et al performed four in utero BMTs for primary immunodeficiencies ${ }^{11}$ (F Porta, personal communication). Two required postnatal BMT, none have B cell engraftment, and one has poor $\mathrm{T}$ cell function (10\% normal). Death in utero resulting from GvHD, an occurrence predicted to be unlikely because of the naivety of fetal immune systems, has also been reported. The single case report has only short term follow up and the details of immune function are not detailed. ${ }^{12}$ As normal $\mathrm{B}$ cell function after in utero BMT has yet to be achieved, these patients require long term IVIG. Patients requiring long term IVIG, such as those with hypogammaglobulinaemia and combined variable immunodeficiency, have problems with sinopulmonary disease, and it is likely that patients on long term IVIG after in utero BMT would be at risk of similar problems.

Early postnatal BMT has been successful in that all our patients survived BMT. No deaths occurred from infection, the major cause of death in children diagnosed and transplanted later in life when they have already become infected with potentially fatal organisms. Those in our cohort who developed infective complications have all cleared viral infections and not suffered major morbidity as a result. All but one have good $\mathrm{T}$ cell function, and function in the remaining patient is improving six months after BMT. Seven of eight evaluated more than one year after BMT (88\%) have made adequate seroresponses to vaccination against tetanus and Haemophilus influenzae type B; a further three are currently being evaluated. GvHD has not been a long term problem, with resolution of all cases, except possibly for case 7 . Although the long term outlook of immune function in two of our patients remains uncertain, our results overall are good.

We conclude from our results that, when there is a positive family history of SCID, urgent postnatal transfer to a specialised unit for a conventional BMT is preferable to in utero transplantation.

1 Glanzmann E, Riniker P. Essentielle lymphocytophthise: ein neues Krankheitsbild aus der sauglingspathologie. Ann Paediatr 1950;175:1-32.

2 Gatti RA, Meuwissen HJ, Allen HD, et al. Immunological reconstitution of sex-linked lymphopenic immunological deficiency. Lancet 1968;2:1366-9.

3 Reisner Y, Kapoor N, Kirkpatrick D, et al. Transplantation for severe combined immunodeficiency with HLA-A, B, $\mathrm{D}, \mathrm{DR}$ incompatible parental marrow cells fractionated by soybean agglutinin and sheep red blood cells. Blood 1983;61:341-8 
4 Noguchi M, Yi H, Rosenblatt HM, et al. Interleukin-2 receptor $\gamma$ chain mutation results in X-linked severe com-

5 Macchi P, Villa A, Giliani S, et al. Mutations of JAK-3 gene in patients with autosomal severe combined immunodeficiency. Nature 1995;377:65-8.

6 Schwarz K, Gauss GH, Ludwig L, et al. RAG mutations in human B cell negative SCID. Science 1996;274:97-9.

7 Puel A, Ziegler SF, Buckley RH, et al. Defective IL7R expression in $\mathrm{T}-\mathrm{B}+\mathrm{NK}+$ severe combined immunodeficiency. Nat Genet 1998;20:394-7.

8 Giblett ER, Anderson JE, Cohen F, et al. Adenosinedeaminase deficiency in two patients with severely impaired cellular immunity. Lancet 1972;2:1067-9.

9 Flake AW, Roncaralo MG, Puck J, et al. Treatment of $\mathrm{X}$-linked severe combined immunodeficiency by in utero transplantation of paternal bone marrow. $N$ Engl $7 \mathrm{Med}$ 1996;335:1806-10.
10 Touraine JL, Raudrant D, Laplace S, et al. Stem cell transplants in utero for genetic diseases: treatment and a model for induction of immunological tolerance. Tran

11 Porta F, Lanfranchi A, Verardi R, et al. Il trapianto prenatale e postnatale docellule staminali emopoietiche in bambini affetti da immunodeficienza primitiva. Ann Ist Super Sanita 1999;35:315-28

12 Gil J, Porta F, Bartolome J, et al. Immune reconstitution after in utero bone marrow transplantation in a fetus with severe combined immunodeficiency with natural killer cells. Transplant Proc 1999;31:2581.

13 Wengler GS, Lanfranchi A, Frusca $\mathrm{T}$, et al. In-utero transplantation of parental CD34 haematopoietic progenitor cells in a patient with X-linked severe combined immunodeficiency. Lancet 1996;348:1484-7.

14 Buckley RH, Schiff SE, Schiff RI, et al. Hematopoietic stem-cell transplantation for the treatment of severe com-
bined immunodeficiency. N Engl f Med 1999;340:508-16.

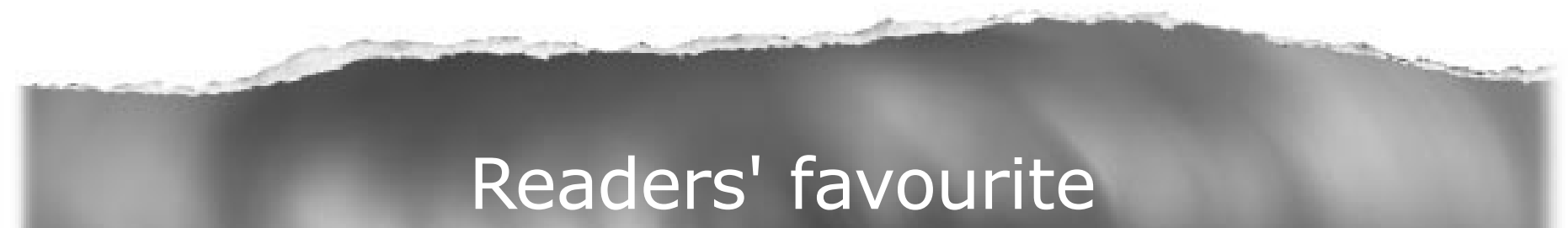

Top 10

Click on the "Top 10" button on the homepage to see which are the best read articles each month

www.archdischild.com 